\title{
BMJ Open Healthcare professionals in COVID-19- intensive care units in Norway: preparedness and working conditions: a cohort study
}

\author{
Irene Lie (D) , ${ }^{1}$ Siv Stafseth, ${ }^{2,3}$ Laila Skogstad, ${ }^{4,5}$ Ingvild Strand Hovland, ${ }^{6}$ \\ Haakon Hovde, ${ }^{7}$ Øivind Ekeberg, ${ }^{8}$ Johan Ræder ${ }^{9,10}$
}

To cite: Lie I, Stafseth S, Skogstad L, et al. Healthcare professionals in COVID19-intensive care units in Norway: preparedness and working conditions: a cohort study. BMJ Open 2021;11:e049135. doi:10.1136/ bmjopen-2021-049135

- Prepublication history and additional supplemental material for this paper are available online. To view these files, please visit the journal online (http://dx.doi.org/10.1136/ bmjopen-2021-049135).

Received 18 January 2021 Accepted 15 September 2021

D Check for updates

(c) Author(s) (or their employer(s)) 2021. Re-use permitted under CC BY-NC. No commercial re-use. See rights and permissions. Published by BMJ.

For numbered affiliations see end of article.

Correspondence to

Dr Irene Lie; irene.lie@ous-hf.no

\section{ABSTRACT}

Objective To survey the healthcare professionals' background and experiences from work with patients with COVID-19 in intensive care units (ICUs) during the first wave of the COVID-19 pandemic in Norway.

Design Observational cohort study.

Setting COVID-ICUs in 27 hospitals across Norway. Participants Healthcare professionals ( $n=484)$ : nurses $(81 \%)$, medical doctors $(9 \%)$ and leaders $(10 \%)$, who responded to a secured, web-based questionnaire from 6 May 2020 to 15 July 2020.

Primary and secondary measures Healthcare professionals': (1) professional and psychological preparedness to start working in COVID-ICUs, (2) factors associated with high degree of preparedness and (3) experience of working conditions.

Results The age of the respondents was $44.8 \pm 10$ year (mean \pm SD), $78 \%$ were females, $92 \%$ had previous ICU working experience. A majority of the respondents reported professional (81\%) and psychological $(74 \%)$ preparedness for working in COVID-ICU. Factors significantly associated with high professional preparedness for working in COVID-19-ICU in a multivariate logistic model were previous ICU work experience $(p<0.001)$ and participation in COVID-ICU simulation team training $(p<0.001)$. High psychological preparedness was associated with higher age $(p=0.003)$, living with spouse or partner $(p=0.013)$, previous ICU work experience $(p=0.042)$ and participation in COVIDICU simulation team training $(p=0.001)$. Working with new colleagues and new professional challenges were perceived as positive in a majority of the respondents, whereas $84 \%$ felt communication with coworkers to be challenging, $46 \%$ were afraid of being infected and $82 \%$ felt discomfort in denying access for patient relatives to the unit. Symptoms of sweating, tiredness, dehydration, headache, hunger, insecurity, mask irritation and delayed toilet visits were each reported by more than $50 \%$.

Conclusions Healthcare professionals working during the first wave of COVID-ICU patients in Norway were qualified and prepared, but challenges and potential targets for future improvements were present.

Trial registration number NCT04372056.
Strengths and limitations of this study

- This is a national study covering all COVID-19 intensive care units (ICUs) in Norway during the first wave of the pandemic.

- Nurses, medical doctors and leaders in COVID-ICUs were included.

- The study questionnaire focuses on the background and experiences of healthcare professionals regarding both preparation, preparedness and working conditions in COVID-19 ICUs.

- The exact response rate is unknown, due to incomplete national registry of ICU employed healthcare professionals.

- The experience from ICU-COVID workers in Norway may not be representative for other countries with a much higher incidence of ICU-COVID and different timing of the first wave of the pandemic.

\section{INTRODUCTION}

On 11 March 2020, WHO declared the coronavirus outbreak to be a pandemic. By 14 December 2020, over 70 million COVID-19 cases were reported, and 1.6 million patients had died, according to WHO. ${ }^{1}$ The pandemic induced a worldwide challenge, with the need to rapidly reshape intensive care units (ICUs) facilities and retrain healthcare personnel, including use of cumbersome personal protective equipment (PPE), as described in Italy. $^{2}$ Nurses, medical doctors and leaders (healthcare professionals) working in the front line with COVID-ICU patients also put themselves at potential high risk of being infected with COVID-19 virus. ${ }^{3}$ In addition, they perceived psychological stress related to the high numbers of dead patients. ${ }^{45}$ These aspects are discussed in Cooper's model on the dynamics of work stress, which focuses on an individual level of stress due to new demanding and potentially dangerous tasks 
during work, ${ }^{6}{ }^{7}$ for example, working front line as professionals in COVID-ICUs. ${ }^{8}$

For patients to survive serious COVID-19 disease with respiratory failure, intensive care treatment with optimal oxygenation, assisted ventilation and eventually ventilator treatment is crucial. ${ }^{9}$ Although the COVID-19-ICU patients basically have a simple single organ failure, that is, the lungs, the ICU treatment is complicated and very demanding in terms of resources. The personnel have to protect themselves extensively from being infected through droplets or aerosols generated by the patients. ${ }^{10}$ Also, it has been shown that the need for ventilator support may be very prolonged, that is, many weeks in some cases, and demanding in terms of secondary organ complications. ${ }^{11}$ In selected younger patients, the extensive treatment with extracorporeal membrane oxygenation may be an option. ${ }^{12}{ }^{13}$ Also, as serious COVID-19 airway disease was a completely new disease at the start of 2020, discussions concerning evidence for the optimal treatment methods ${ }^{9}$ were significant sources of frustration among ICU workers at that time.

During the first wave of COVID-19 until 15 July, the total number of COVID-ICU patients in Norway was 226, and $43(19 \%)$ died $^{14}$ compared with an in-ICU mortality rate of $41.6 \%$ across international COVID-19 studies until 31 May $2020 .{ }^{15}$ Norway has a lower number of intensive care beds, only 8 per 100000 inhabitants, compared with the European average of approximately $11.5 .{ }^{16}$ Thus, the ICU bed occupancy is usually in the $90 \%-100 \%$ range in Norway.

At the start of the pandemic, there were a number of international reports on inadequate PPE, ${ }^{101718}$ fear of getting infected among healthcare personnel ${ }^{3} 1019$ and lack of adequate preparation, including lack of protective devices and absence of simulation training. ${ }^{182021}$ In March 2020, registered nurses (RNs) ( $\mathrm{n}=1464$ ) across Norway responded to a survey focusing on working with COVID-19 patients, mostly outside the ICU setting. The nurses described a feeling of being invaded, working long shifts with few breaks, lack of equipment, hectic workload for the leaders, as well as private challenges. ${ }^{17}$ Also, in an early web-based worldwide study on healthcare workers in COVID-ICUs $(\mathrm{n}=1797)$, adverse effects of PPE; such as heat, thirst, pressure areas, headaches, inability to use the bathroom and extreme exhaustion, were reported. ${ }^{18}$

There is a lack of studies focusing on the experiences and views of healthcare professionals caring for the most critically ill patients regarding both preparation and working conditions in COVID-19 ICUs. The objectives of this study were to survey Norwegian intensive healthcare professionals': (1) preparedness to start working in COVID-ICUs, (2) factors contributing to professional and psychological preparedness for working in COVID-ICUs and (3) daily workingconditions inside ICUs during the first wave of the pandemic.

\section{METHODS}

\section{Study design}

This is a prospective, longitudinal observational cohort study and is reported according to the Strengthening the Reporting of Observational Studies in Epidemiology cohort checklist. ${ }^{22}$

\section{Study setting, population and inclusion process}

The baseline data collection on healthcare professionals working in COVID-ICUs was conducted from 6 May 2020 to 15 July 2020. An email invitation, including general information about the study, with a direct link to the secured web-based questionnaire, was sent to leaders (nurses and medical doctors) of all 28 hospitals with registered COVID-19 patients in ICU units in Norway. The local leaders were asked to redistribute the invitation to all relevant personnel at their site. Potential respondents were then informed about activating a direct link to electronic consent, then a second step to the web-based questionnaire. Both steps included login by a secured personal bank identification login. Inclusion criteria were: nurses, medical doctors and local ICU-unit leaders (healthcare professionals) in ICUs with COVID-19 patients. Also included were personnel who had been allocated from regular positions as nurse anaesthetist, operating room nurse, $\mathrm{RN}$ at ward or general anaesthesiologist to COVID-ICU. Those not being Norwegian citizens as defined by social security number were excluded.

\section{The questionnaire}

The baseline study questionnaire was a composite selection of 181 validated questions into eight parts, with 88 (Part I-IV, (online supplemental file 1) relevant for the aims of this report. Further data from 93 questions (Parts IV-VIII) of the healthcare professionals' psychologicalsocial health and the COVID-ICU leaders' experiences, will be presented separately. Part I of the questionnaire focused on demographic characteristics of the healthcare professionals' background, for example, age, profession, number of years working in ICUs (total of 14 variables). Part II focused on preparations for working in the COVID-ICU, for example, information received, professional competence (total of ten variables). Part III of the questionnaire focused on the daily working conditions in the COVID-ICU, including use of PPE, the professional role, communication and cooperation across disciplines, and finally, some questions related to COVID-ICU patients and relatives (a total of 60 variables). Four questions included from Part IV of the questionnaire focused on private COVID-19 aspects for example, Have been infected or in quarantine?

Out of the questions in parts I-IV, nine were adapted from a previous study of rescue workers during the terror attacks in Norway 22 July $2011 .^{23}$ Then 79 questions were included as a result of a modified Delphi method decision process $^{24}$ among the expert author group. The goals were to construct clinically meaningful and relevant questions, and to improve face and validity of the questionnaire. ${ }^{24}$ 
The questionnaire was sent five times to the interdisciplinary expert group, with responses aggregated and shared with the group after each time until unanimous decision was made on the final version. The questions asked for either numbers, yes/no answers or selection among alternatives along five-point Likert scales. The questionnaire was basically constructed for the respondent to answer each question mandatory in order to answer the next.

\section{Pilot}

A pilot test of the questionnaire was conducted on expert medical doctors and critical care nurses $(n=5)$. Minor adjustment of the content of three questions was subsequently performed before the study started.

\section{Patients and public involvement \\ No patients were involved.}

\section{User involvement}

A critical care nurse leading the educational committee in The Norwegian Association of Critical Care Nurses, also holding a master's degree in critical care nursing and working as a critical care nurse in a COVID-ICU and a clinical simulation unit, was the formal user representative. He has participated from the project inception, participating in the design of the study, as well as attending all research group meetings and being a part of the author group.

\section{Statistical analyses and missing data}

Data were analysed using IBM SPSS Statistics V.27. Descriptive analysis was performed for all variables in the study. Then transformation of values into dichotomous variables for relevant variables (previous experience with COVID-ICU like tasks and simulation training ( $0=$ never and $1=y e s$, once or yes, several times $)$ were done, to compare with data of professional and psychological preparedness to start working in COVID-ICUs $(0=$ no; not at all or to a small degree, $1=y e s ;$ partly or to a high/ very high degree). Univariate analysis included $\chi^{2}$ test (sex, marital status, number of people in household (one vs more), personal risk factors for developing serious COVID-19 (yes vs none), profession (medical doctor or nurse), ICU work experience (yes vs none) and t-test for the continuous variables of age, and years of professional experience as MD or nurse.

To further assess the association between factors contributing to the dependent variables professional and psychological preparedness for working in COVID-ICUs, two multivariate logistic regression analysis with a backward elimination procedure was performed. All relevant variables (see above) were included in the multivariate analysis, and thereafter dropped step by step until remaining variables were considered to have significant and independent contribution to the dependent variables $(\mathrm{p}<0.05){ }^{25}$ Age and sex were forced into all steps of the model. The categorical variable 'date for start-up working' were transformed to a dummy variable. The models of professional preparedness (model 1), and psychological preparedness (model 2) were examined for multicollinearity, Cox-Snell R-squared and Nagelkerke R-squared before the HosmerLemeshow test the goodness of model fit.

Moreover, the data protection officer, the head of research and leaders at all relevant levels of COVIDICUs in Norway had to approve the study locally for their participation. Informed consent and data from the study questionnaire were stored at Services for Sensitive Data at University of Oslo, Norway.

\section{RESULTS}

\section{Pre-COVID demographic characteristics}

Data were collected in the period from 6 May 2020 to 15 July 2020 from 484 healthcare professionals representing 27 out of 28 ICU units in Norway with COVID-19 patients. One ICU unit did not participate due to delays and problems with local approval of involvement. Apart from 44 missing data on years of professional working, 4 missing data on full-time job, no data were missing due to the mandatory and sequential construct of the questionnaire.

Most (92\%) of the respondents had experience of working in an ICU setting at the outbreak of the pandemic. At the time of their response, 219 (45\%) were still working in a COVID-ICU. Three hundred and ninetythree $(81 \%)$ were affiliated with a hospital in the larger South-East region of Norway, which represents about $50 \%$ of the total Norwegian population. The demographic characteristics are presented in table 1 . The respondents were, in general, middle aged with highly relevant professional experience for working in COVID-ICUs. A majority of respondents were nurses $(81 \%), 9 \%$ were medical doctors and $10 \%$ defined themselves as 'leaders'.

\section{Preparation for work in COVID-ICU}

The medical doctors and nurses reported a median of 14.0 days (range 0-90 days, SD 13.1) to prepare for working in a COVID-ICU unit, whereas $120(25 \%)$ had less than a week to be prepared. Almost two out of three respondents felt prepared to work in COVID-ICUs at a partly to a very high degree (table 2 ), and $57 \%$ had participated in simulation training dedicated to the COVID-ICU setting.

\section{Interference with preparedness for working in COVID-ICU Non-adjusted (for covariate influence) correlation}

Healthcare professionals who experienced to be professionally prepared (ie, partly or high/very high degree) were older (mean 45.3 vs $43.0, \mathrm{p}=0.045$ ) had more years of professional experience as medical doctor or nurse (mean 19.8 vs $17.4, \mathrm{p}=0.038$ ), had ICU work experience (371 vs 20, $\mathrm{p}<0.001$ ), had previous experience with COVID-19 like work tasks (327 vs $64 \mathrm{p}=0.004$ ), as well as experience with simulation training in team working with COVID-ICU patients (189 vs 202, p<0.001). Similarly, the variables older age (45.8 vs $42.06, \mathrm{p}<0.001)$, having a spouse/partner (299 vs $92, \mathrm{p}=0.005$ ), years of 
Table 1 Pre-COVID demographic characteristics of respondents in the COVID-ICU healthcare professional study $(\mathrm{n}=484)$

\begin{tabular}{ll}
\hline Age, (range 24-65): mean (SD) & $44.8(10)$ \\
$\geq 60$ years, $\mathrm{n}(\%)$ & $36(7)$ \\
\hline Female sex, $\mathrm{n}(\%)$ & $377(78)$ \\
\hline Married or partner, $\mathrm{n}(\%)$ & $362(75)$ \\
\hline Had children (range 1-3), $\mathrm{n}(\%)$ & $364(75)$ \\
No of persons living in household, $\mathrm{n}(\%)$ & \\
$\quad$ One person & $103(21)$ \\
\hline Two persons or more & $381(79)$
\end{tabular}

Presence of risk factors of developing serious COVID-19 disease, $\mathrm{n}(\%)$

\begin{tabular}{|ll}
\hline Any risk factor, $\mathrm{n}(\%)$ & $65(13)$ \\
\hline $\mathrm{BMI}>30$ & $23(5)$ \\
\hline Heart disease including high blood pressure & $19(4)$ \\
\hline Lung disease & $10(2)$ \\
\hline Immune disease & $8(2)$ \\
\hline Age 65 & $1(0)$ \\
\hline Diabetes mellitus & $1(0)$ \\
\hline Other & $3(1)$ \\
\hline Profession, $\mathrm{n}(\%)$ & \\
\hline Registered nurse (RN), $\mathrm{n}(\%)$ & $392(81)$ \\
\hline Critical care nurse & $305(63)$ \\
\hline Nurse anaesthetist & $24(5)$ \\
\hline Operating room nurse & $7(1)$ \\
\hline Paediatric nurse & $1(0)$ \\
\hline Other RN & $55(12)$ \\
\hline Medical doctor (MD) & $43(9)$ \\
\hline General anaesthesiologist including under & $29(6)$ \\
\hline ICU specialisation* & \\
\hline Anaesthesiologist with ICU specialisation* & $10(2)$ \\
\hline Other MD & $4(1)$ \\
\hline Leader (RN or MD), n (\%) & $49(10)$ \\
\hline
\end{tabular}

Professional experience

Years of professional experience, all participants pooled, $n$ (\%)

$\begin{array}{ll}<1 \text { year } & 51(10) \\ 1 \text { - } 5 \text { years } & 136(28) \\ >5 \text { years } & 297(61) \\ \begin{array}{l}\text { MD, years of professional experience (range } \\ \text { 0-35), mean (SD) }\end{array} & 17.4(9) \\ \begin{array}{l}\text { RN, years of professional experience, nurse } \\ \text { (range 3-42), mean (SD) }\end{array} & 19.6(9) \\ \begin{array}{l}\text { Previous ICU experience, n (\%) } \\ \begin{array}{l}\text { Previous experience with COVID-19-like work } \\ \text { tasks, n (\%) }\end{array}\end{array} \\ \begin{array}{l}\text { Experience with patients with serious lung } \\ \text { disease, n (\%) }\end{array} & 70(14) \\ \end{array}$

Continued
Table 1 Continued

$\begin{array}{ll}\begin{array}{l}\text { Experience with working shifts in isolate } \\ \text { room, } \mathrm{n}(\%)\end{array} & 280(58) \\ \begin{array}{l}\text { Infected with COVID-19 virus (positive test) } \\ \text { before responding to survey, } \mathrm{n}(\%)\end{array} & 6(1) \\ \text { Have been in quarantine, } \mathrm{n}(\%) & 122(25)\end{array}$

*Intensivist.

BMI, body mass index; ICU, intensive care unit.

professional experience (20.4 vs 16.4, $\mathrm{p}<0.001)$, nursing profession ( 315 vs $43, \mathrm{p}=0.032$ ), previous experience with COVID-19 like work tasks (301 vs 57, $\mathrm{p}=0.005$ ) and simulation training in team working with COVID-ICU patients (171 vs $187, \mathrm{p}=0.001$ ) were significantly associated with psychological preparedness. Early or late start of first day working with COVID-ICU patients resulted in significantly less professional and psychological preparedness than starting between 8 March and 23 March $(\mathrm{p}<0.05)$.

Correlation adjusted for influence of covariates

In the multivariate logistic analyses (table $3 \mathrm{~A}, \mathrm{~B}$, online supplemental files 2 and 3 ), three associations remained statistically significant with professional preparedness: healthcare professionals with previous ICU work experience $(p<0.001)$, personnel who had participated in simulation with a team similar to working with COVID-ICU patients $(\mathrm{p}<0.001)$ and first day of start-up work remained significant at a $\mathrm{p}=0.004$ level for week start 16 March compared with 23 March. Similarly for the psychological preparedness, five variables remained statistically significant in the multivariate analyses; higher age $(\mathrm{p}=0.003)$, having a spouse or a partner $(\mathrm{p}=0.013)$, previous experience with COVID-19 like work tasks $(\mathrm{p}=0.042)$, experience with simulation training in team working with COVID-ICU patients $(\mathrm{p}=0.001)$, and intermediate date of first day with patients $(\mathrm{p}=0.029)$.

\section{Experience of information from the COVID-ICU leader}

Information from the leader during the preparation for the COVID-ICU working period was generally perceived as informative and clear by $212(44 \%)$ respondents and reassuring by $146(30 \%)$. However, there was a minority with agreement (several responses were possible) on some negative statements such as: The information came too late' ( $\mathrm{n}=76$ respondents; $16 \%)$, 'The information was too scarce, did not address all relevant aspects' $(n=120$; $25 \%)$, 'The information was unclear, did not give good answers' ( $\mathrm{n}=98 ; 20 \%)$, 'The information was deficient in the start-up phase' $(\mathrm{n}=165 ; 34 \%)$ and 'The information was deficient even long after the start-up phase' $(n=83$; $17 \%)$.

\section{Daily working conditions in the COVID-ICU}

Table 4 describes the respondents' working schedule (part A), and number of patient contacts (part B) in the COVID-ICUs. Almost half of the healthcare professionals 
Table 2 Preparations for working in COVID-ICU, $(n=484)$

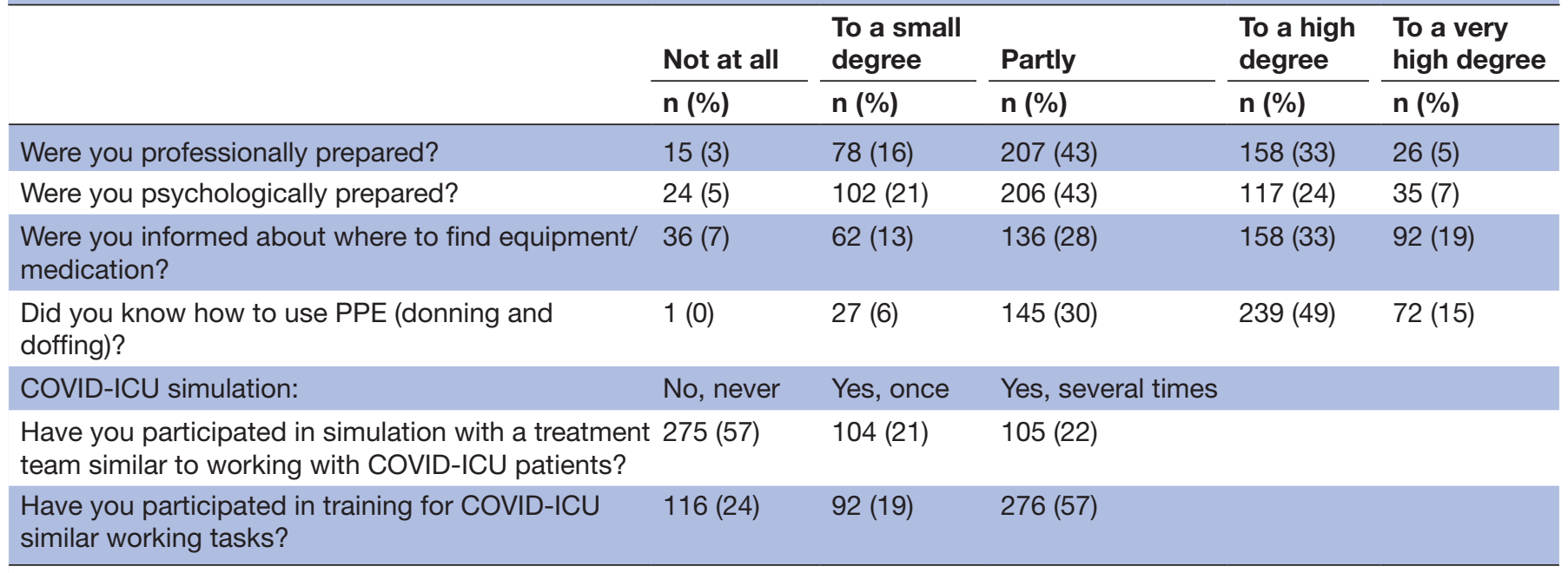

ICU, intensive care unit; PPE, personal protective equipment.

were working in their ordinary ICU, which, however, was reorganised and rebuilt into a dedicated COVID-cohort.

\section{Work role of healthcare professionals in the COVID-ICU}

Almost all of the respondents experienced change in their everyday working logistics, as 219 (45\%) had a change in their shifts and 196 (40\%) experienced working in a nonfamiliar COVID-ICU. A smaller proportion, 57 (12\%), worked in several COVID-ICUs. Moreover, $381(79 \%)$ had experience from working in a team with one or more new colleagues. This setting created some distress, described as not knowing the competence of the new colleague $(\mathrm{n}=166 ; 34 \%)$, feeling increased responsibility $(\mathrm{n}=66$; $14 \%)$, exhaustion $(\mathrm{n}=61 ; 13 \%)$ and insecurity in psychological reactions $(\mathrm{n}=5 ; 1 \%)$, whereas $81(17 \%)$ reported no problems.

The respondents were aware of their obligations in the COVID-ICU to a high or a very-high degree $(n=379$; $78 \%)$ and only $53(11 \%)$ experienced having work tasks with concomitant lack of resources. Two hundred and ten $(43 \%)$ experienced some degree (small to very high) of duties at work conflicting with their personal values. For $17(4 \%)$, the conflict was perceived at a high or very high levelled, whereas it was not a problem for $274(57 \%)$. A large majority of the respondents reported their experience from contact with the COVID-ICU patients as valuable on a professional $(\mathrm{n}=346 ; 71 \%)$ and personal $(\mathrm{n}=286 ; 59 \%)$ level, that is, high degree or very high degree. A smaller number of respondents experienced 'not at all 'or 'in a small degree' the value of working with COVID-ICU patients; professionally low value for 27 respondents $(6 \%)$ or personally low value for 52 respondents $(11 \%)$.

\section{PPE and fear of being infected with COVID-19}

In general, 222 (46\%) respondents were afraid of being infected with COVID-19 at work. A diversity of personal protective masks were used (many used more than one type): P2 was used by $340(70 \%)$, P3 ( $\mathrm{n}=359 ; 74 \%)$, gas mask with changeable filter $(n=54 ; 11 \%)$, mouth mask not approved for air infection $(\mathrm{n}=75 ; 15 \%)$ and ordinary mouth mask $(243 ; 50 \%)$. Almost two out of three $(\mathrm{n}=309$; $64 \%$ ) experienced problems with a tight mouth mask, although assistance was provided on mask application in about half of the cases $(n=263 ; 53 \%)$. An increased fear of getting COVID-19 infection ( $\mathrm{n}=275 ; 57 \%)$ was related to insufficient mask standard. Advice and help with the PPE dressing was reported to be provided only in the start of the COVID-ICU working period for $91(19 \%)$ and all the time for $152(31 \%)$, whereas $152(31 \%)$ received help to a variable extent later on. Absence of advice or assistance in dressing for COVID-ICU work was experienced by 89 (19\%). Moreover, 381 (79\%) had worked in a room/isolate without protective negative air pressure, and of that $161(33 \%)$ experienced an increased fear of COVID-19 infection as a result.

\section{Healthcare professionals' symptoms experienced in COVID- ICU}

A large majority of the healthcare professionals experienced overt symptoms directly related to their COVID-ICU work. The fraction of replies in the 'partly' to 'very high degree' range were marks and wounds on the face and/or behind the ears after use of mask and glasses were reported by $408 / 484(84 \%)$ of the respondents, and $263(53 \%)$ of them got assistance to reduce the marks/wounds. The six highest-ranked (from high to low) other symptoms during work were: 449/460 being warm/sweating (97\%), 447/463 being tired (97\%), 442/460 being dehydrated (96\%), 429/464 having a 'heavy head' (92\%), 381/458 had difficulties in getting to the toilet (83\%) and 367/461 having headache (79\%) (as presented in online supplemental file 4 ). Moreover, experienced were hunger $(n=280 ; 61 \%)$, insecurity $(n=270$; $58 \%)$, anger $(n=139 ; 30 \%)$, heartbeat $(n=195 ; 23 \%)$, fear 


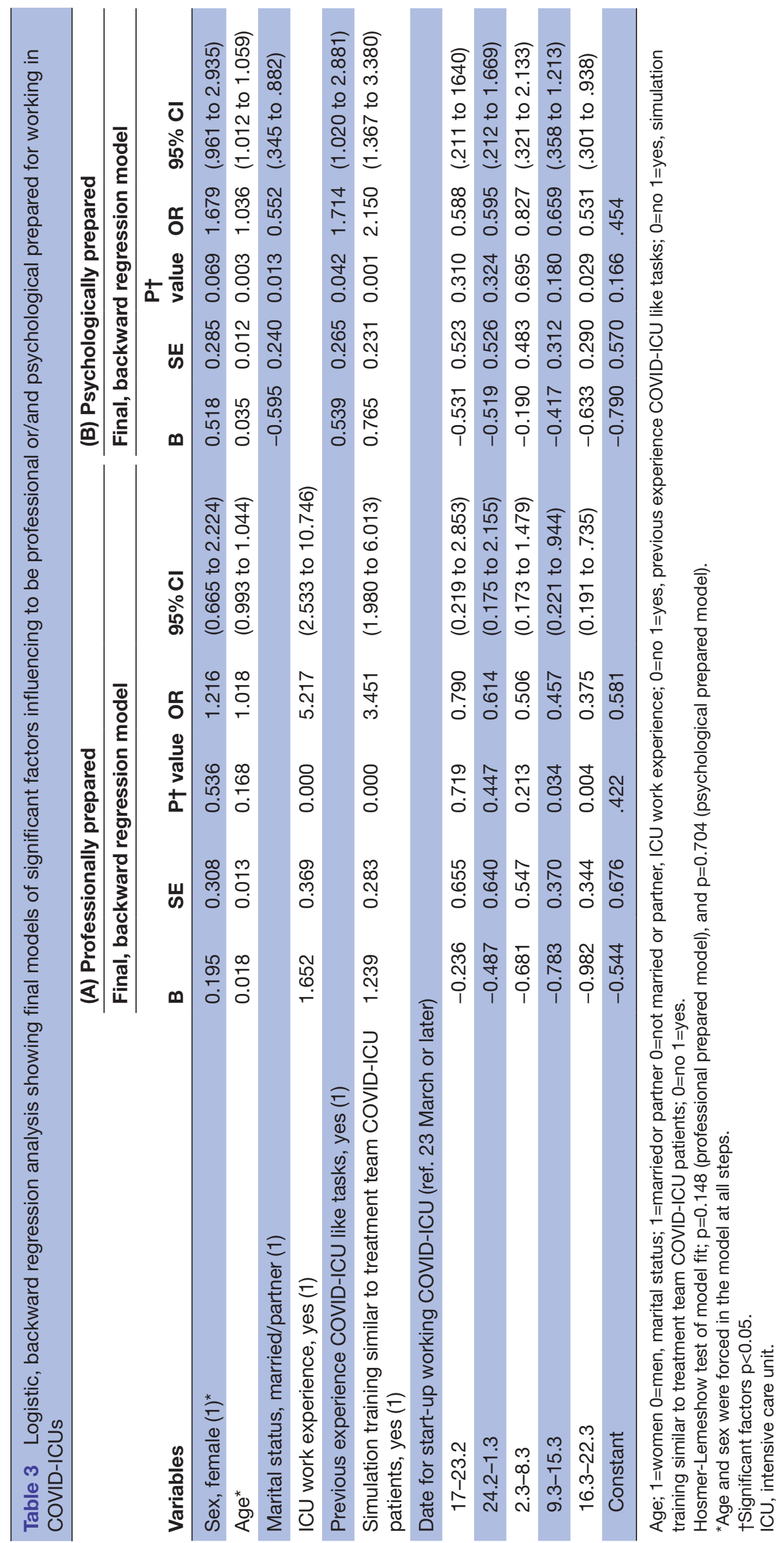




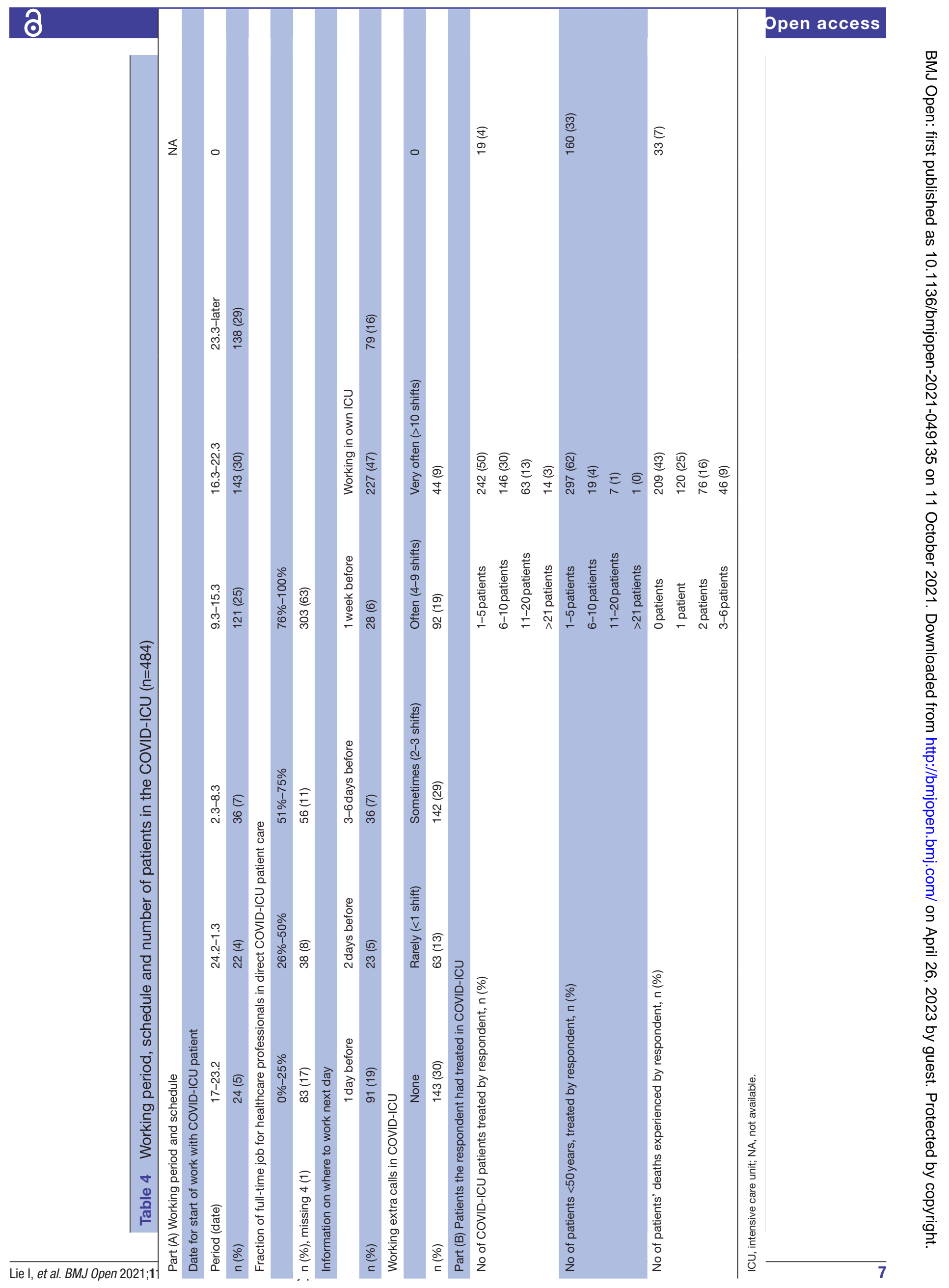


Table 5 Experience with communication with colleagues (part A) and patients' relatives (part B), when working in COVID-ICU, $(n=484)$

\begin{tabular}{|c|c|c|c|c|c|}
\hline Not at all & $\begin{array}{l}\text { To a small } \\
\text { degree }\end{array}$ & Partly & $\begin{array}{l}\text { To a high } \\
\text { degree }\end{array}$ & $\begin{array}{l}\text { To a very high } \\
\text { degree }\end{array}$ & NA \\
\hline n (\%) & n (\%) & n (\%) & n (\%) & n (\%) & $\overline{n(\%)}$ \\
\hline
\end{tabular}

Part (A): Cooperation and communication with colleagues

Professional cooperation in COVID-ICU

\begin{tabular}{|c|c|c|c|c|c|c|}
\hline Good & $3(1)$ & $13(3)$ & $106(22)$ & $211(43)$ & $140(29)$ & $11(2)$ \\
\hline Professionally enriching & $7(1)$ & $30(6)$ & $134(28)$ & $189(39)$ & $117(24)$ & $7(2)$ \\
\hline Exhausting & $10(2)$ & $79(16)$ & $158(33)$ & $144(30)$ & $81(17)$ & $12(2)$ \\
\hline \multicolumn{7}{|l|}{ Social cooperation in COVID-ICU } \\
\hline Good & $7(1)$ & $35(7)$ & $141(29)$ & $185(38)$ & $104(22)$ & $12(3)$ \\
\hline Professionally enriching & $17(3)$ & $70(15)$ & $169(35)$ & $159(33)$ & $53(11)$ & $16(3)$ \\
\hline Exhausting & $20(4)$ & $103(21)$ & $177(37)$ & $113(23)$ & $55(12)$ & $16(3)$ \\
\hline \multicolumn{7}{|l|}{ Practical cooperation in COVID-ICU } \\
\hline Good & $1(0)$ & $19(4)$ & $155(32)$ & $223(46)$ & $77(16)$ & $9(2)$ \\
\hline Professionally enriching & $7(1)$ & $54(11)$ & $177(37)$ & $171(35)$ & $61(13)$ & $14(3)$ \\
\hline Exhausting & $9(2)$ & $66(14)$ & $215(44)$ & $123(25)$ & $58(12)$ & $13(3)$ \\
\hline \multicolumn{7}{|c|}{ Experience of communication with colleagues in COVID-ICU } \\
\hline No problems & $17(4)$ & $64(13)$ & $233(48)$ & $109(23)$ & $35(7)$ & $26(5)$ \\
\hline Misunderstandings & $25(5)$ & $133(28)$ & $194(40)$ & $80(17)$ & $30(6)$ & $22(4)$ \\
\hline Repetition of questions/ answers & $4(1)$ & $45(9)$ & $117(24)$ & $155(32)$ & $142(30)$ & 21(4) \\
\hline Strenuous/tiring & $10(2)$ & $49(10)$ & $144(30)$ & $154(32)$ & $106(22)$ & $21(4)$ \\
\hline \multicolumn{7}{|l|}{ Part (B): Communication with relatives } \\
\hline \multicolumn{7}{|l|}{ Communication with relatives } \\
\hline No problem & $8(2)$ & $28(6)$ & $171(35)$ & $127(26)$ & $30(6)$ & $120(25)$ \\
\hline Misunderstandings & $34(7)$ & $181(37)$ & $119(25)$ & $24(5)$ & $10(2)$ & $116(24)$ \\
\hline Repetition of questions/answers & $17(4)$ & $87(18)$ & $136(28)$ & $87(18)$ & $34(7)$ & $123(25)$ \\
\hline Strenuous/tiring & $28(6)$ & $120(25)$ & $123(25)$ & $69(14)$ & $27(6)$ & $117(24)$ \\
\hline
\end{tabular}

.ICU, intensive care unit; NA, not applicable.

$(\mathrm{n}=133 ; 29 \%)$, indifference $(87 ; 19 \%)$, claustrophobia $(\mathrm{n}=97 ; 23 \%)$, confusion symptoms $(\mathrm{n}=96 ; 21 \%)$ and others $(\mathrm{n}=81 ; 39 \%)$.

\section{Respondents' experiences with cooperation and communication in COVID-ICUs}

Table 5 describes the graded experience of cooperation and communication with colleagues (part A) and communication with relatives (part B). A majority of the respondents $340(70 \%)$, reported discomfort from having to deny access to visitors of the patients into the COVID-ICU.

\section{DISCUSSION}

The healthcare professionals treating COVID-19 patients in ICUs in Norway during the first wave were well-qualified and experienced. The professional and psychological preparedness were high. They had some time for preparations and felt a high degree of professionalism and personal satisfaction during the work in the COVID-ICU. However, the respondents reported heavy workloads, some communication challenges and physical symptoms as a result of protective dressing and masks.

To our knowledge, this is the first national study focusing on healthcare professionals' experiences and views of both preparation and working conditions in COVID-19 ICUs during the first wave of the pandemic.

By 20 February 2020, the first COVID-ICU patient were reported in both Italy ${ }^{2}$ and Norway. Subsequently, however, from 28 February to 25 March, 1591 COVID-19 patients were admitted to ICUs in the Lombardy region in Italia, whereas a total of 226 COVID-19 patients were admitted to the ICUs in Norway until 15 July. ${ }^{26}$ Nevertheless, preparing the COVID-ICUs had to be rapid and extensive since Norway anticipated the same relative numbers of COVID-ICU patients as other countries in Europe. ${ }^{15}$ Norway has a low number of ICU beds compared with Europe ${ }^{16}$ and unlike most other countries, both nurses 
and medical doctors working in ICUs in Norway are, in general, highly trained and specialised in critical care from universities, and there are no other personnel groups, such as nurse-assistants, respiratory therapists, etc involved with direct routine bedside work.

ICU healthcare professionals, foremost in China, Italy and France only had a few days to prepare for COVID-ICU patients, ${ }^{27}$ similar to $25 \%$ of the respondents $(n=120)$ in our study, who had less than a week to prepare. In our study, as expected, those who started to work with patients before 9 March were less prepared than those starting during the two subsequent weeks. However, and surprisingly, the preparedness were then reduced for those starting after 23 March. This may be explained by a larger number of ICU patients at the same time in the period after 23 March, mandating small ICU units to start treatment of such patients, which so far had been handled by the larger and more experienced units.

Although $57 \%$ of the respondents had never participated in simulation with treatment teams similar to working with COVID-ICU patients, they experienced being professionally and psychologically prepared for working in COVID-ICUs, in a partly to a very high degree at $81 \%$ and $74 \%$, respectively. These positive results may be due to the highly applicable professional experience of the respondents relevant for the critically ill patients with COVID-19, for example, 92\% had previous ICU working experience. Somewhat surprisingly, number of years as professionals or having no risk factors of severe COVID-19 disease were not associated with better preparedness in these analyses. This may be due most respondents having more than 5 years of professional experience, and very few respondents were older than 60 years, respectively. Interestingly, being older and having a spouse or a partner, increased the likelihood of being psychologically prepared, whereas these variables had no impact on professional preparedness. Simulation training were significant in order to increase preparedness, both professionally and psychologically. This is supported by a review article focusing on preparing the ICU for the COVID-19 pandemic. ${ }^{20}$ Another report on in situ simulation to enhance infection control systems in COVID-ICU ${ }^{28}$ underlines the importance of simulation training to ensure the preparedness of healthcare workers. This includes training in the use of PPE, as well as logistics for intubation of COVID-19 patients and for turning patients into prone position.

Numerous studies report the most challenging experience of front-line healthcare professionals working in COVID-ICU is the scarcity and unavailability of certified PPE. ${ }^{10}{ }^{1820}$ Even with the rather low number of COVID-ICU patients during the first wave $(n=226)$ in Norway, when the first COVID-19 patients arrived at a COVID-ICU, the shortage of certified PPEs was a fact. ${ }^{17}$ This challenged and made it somewhat impossible to follow the recommendation for protective equipment for the healthcare professionals from the Norwegian Institute of Public Health, as well as recommendations from the Centers for
Disease Control and Prevention, ${ }^{29}$ and 'key considerations for occupational safety and health during the COVID-19 outbreak" from WHO. ${ }^{1}$ More importantly, the healthcare professionals confirmed a fear of insufficient PPE in our study, with concern for personal safety and worry of transmitting COVID-19 to family/community. ${ }^{3410} 1930-33$ Moreover, healthcare professionals may also have risk factors like high blood pressure or diabetes mellitus ${ }^{34}$ that may cause additional fear of developing COVID-19. Only 65 $(13 \%)$ of the respondents in this study had risk factors for developing serious COVID-19 disease, thus suggesting that local leaders were able to allocate and use non-risk personnel for COVID-ICU work, due to the limited extra total workload imposed on the ICUs in Norway.

A majority of the respondents in our study (84\%) had marks and wounds on the face and/or behind the ears after use of masks and glasses, as well as general symptoms from working in the COVID-ICU. This is in accordance with an international study of healthcare workers in ICUs $(n=2711)$ and a review which reported adverse effects such as heat, thirst, pressure areas in the face, headaches, inability to use the bathroom and extreme exhaustion. ${ }^{185}$ Also, the need for more complete breaks (with doffing of protective dressing) as well as more time for communication with both coworkers and relatives, was evident in the reports from our respondents. ${ }^{36}$

Other challenges in our study were communication and not knowing the competence of the new colleagues within the ICU. Shurlock et al recommend that healthcare professionals in COVID-ICUs wear clear identification labels and use of hand gestures and signals to reinforce questions/answers. ${ }^{37}$

The strength of the present survey was the rapid distribution of the invitation to all relevant Norwegian ICU workers at the end of the first COVID-19 wave, when memories and impressions were fresh. Also, the focus of the survey on those who had worked in the front line with COVID-ICU patients makes interpretation of data more specific and reliable, when compared with surveys that include all kinds of personnel. ${ }^{10} 31$ The limitations of the study include a low precision in getting the invitation to all relevant personnel. The invitations to participate in the study had to be distributed through the hospitals' administration systems at their discretion, in terms of speed and whom to invite. Another limitation is the question of representability since there is no official registry of healthcare professionals (nurses and doctors) who are actually working in the ICUs.

\section{CONCLUSIONS}

The first wave of COVID-19 ICU patients in Norway was limited in terms of extra need for intensive care capacity. The ICUs were prepared for the relative moderate number of COVID-ICU patients and managed with extensive use of pre-existent qualified and experienced healthcare professionals. For further improvement, the institutional efforts should focus on secure and 
comfortable protection to reduce healthcare professionals' risk and fears of becoming COVID-19 infected during their daily work in COVID-ICUs. Although the satisfaction level of the professionals was generally good, the survey revealed the need for more extensive simulation training, comfortable protective equipment and time allowed for breaks and communication.

\section{Author affiliations}

${ }^{1}$ Centre for Patient Centered Heart and Lung Research, Department of Cardiothoracic Surgery, Oslo University Hospital, Oslo, Norway

${ }^{2}$ Department of Postoperative and Intensive Care, Administrative Section, Oslo University Hospital, Oslo, Norway

${ }^{3}$ Department of MEVU, Lovisenberg Diaconal University College, Oslo, Norway ${ }^{4}$ Department of Research, Sunnaas Sykehus HF, Nesoddtangen, Norway ${ }^{5}$ Department of Nursing and Health Promotion, Oslo Metropolitan University, Oslo, Norway

${ }^{6}$ Department of Acute Medicine, Oslo University Hospital, Oslo, Norway

${ }^{7}$ Critical Care Nurses, Norwegian Nurses Association, Oslo, Norway

${ }^{8}$ Division of Mental Health and Addiction, Oslo University Hospital, Oslo, Norway

${ }^{9}$ Department of Anaesthesiology, Oslo University Hospital, Oslo, Norway

${ }^{10}$ Institute of Clinical Medicine, University of Oslo, Oslo, Norway

Contributors IL, JR, SS and ØE contributed to study concept and design, acquisition of data, drafting of the manuscripts and interpretation of data. IL, JR, SS, $\emptyset \mathrm{E}$, LS and ISH contributed to construction of the study questionnaire. LS, ISH and $\mathrm{HH}$ contributed to acquisition of data, contributed to drafting of the manuscripts and interpretation of data.

Funding This research was supported by a grant from the Bergesen foundation, Norway (reference BF-34138)

Competing interests None declared.

Patient consent for publication Not applicable.

Ethics approval The Regional Ethic Committee (REC) (approval number 2020/136144) of South East Norway, and the Data Protection Officer at Oslo University Hospital (approval number 20/09438), Norway.

Provenance and peer review Not commissioned; externally peer reviewed.

Data availability statement Due to the respondents written informed consent data are not available upon request. We have provided an additional, non-author, point of contact that. interested researchers can get in touch with to secure accurancy regarding our data.

Supplemental material This content has been supplied by the author(s). It has not been vetted by BMJ Publishing Group Limited (BMJ) and may not have been peer-reviewed. Any opinions or recommendations discussed are solely those of the author(s) and are not endorsed by BMJ. BMJ disclaims all liability and responsibility arising from any reliance placed on the content. Where the content includes any translated material, BMJ does not warrant the accuracy and reliability of the translations (including but not limited to local regulations, clinical guidelines, terminology, drug names and drug dosages), and is not responsible for any error and/or omissions arising from translation and adaptation or otherwise.

Open access This is an open access article distributed in accordance with the Creative Commons Attribution Non Commercial (CC BY-NC 4.0) license, which permits others to distribute, remix, adapt, build upon this work non-commercially, and license their derivative works on different terms, provided the original work is properly cited, appropriate credit is given, any changes made indicated, and the use is non-commercial. See: http://creativecommons.org/licenses/by-nc/4.0/.

\section{ORCID iD}

Irene Lie http://orcid.org/0000-0002-0461-7812

\section{REFERENCES}

1 World Health Organization, (WHO). Coronavirus disease (COVID-19) pandemic, 2021. Available: https://www.who.int/emergencies/ diseases/novel-coronavirus-2019/interactive-timeline\#!

2 Zangrillo A, Beretta L, Silvani P, et al. Fast reshaping of intensive care unit facilities in a large metropolitan hospital in Milan, Italy: facing the COVID-19 pandemic emergency. Crit Care Resusc 2020;22:91-4.
3 The Lancet. COVID-19: protecting health-care workers. The Lancet 2020;395:922.

4 Shen X, Zou X, Zhong X, et al. Psychological stress of ICU nurses in the time of COVID-19. Crit Care 2020;24:200.

5 Neto MLR, Almeida HG, Esmeraldo Joana D'arc, et al. When health professionals look death in the eye: the mental health of professionals who deal daily with the 2019 coronavirus outbreak. Psychiatry Res 2020;288:112972.

6 Cooper CL, Marshall J. Occupational sources of stress: a review of the literature relating to coronary heart disease and mental ill health. Journal of Occupational Psychology 1976;49:11-28.

7 Cox T, Griffiths A, Rial-González A. Research on work related stress. Bilbao, Spain: European Agency for Safety and Health at Work, 2000: 6-169.

8 Karakose T, Malkoc N. Behavioral and interpersonal effects of the COVID-19 epidemic on frontline physicians working in emergency departments (EDS) and intensive care units (ICUs). Acta Medica Mediterranea 2021;37:437-44.

9 Wilcox SR. Management of respiratory failure due to covid-19. BMJ 2020;369:m1786.

10 Kleinpell R, Ferraro DM, Maves RC, et al. Coronavirus disease 2019 pandemic measures: reports from a national survey of 9,120 ICU clinicians. Crit Care Med 2020;48:e846-55.

11 Mahida RY, Chotalia M, Alderman J, et al. Characterisation and outcomes of ARDS secondary to pneumonia in patients with and without SARS-CoV-2: a single-centre experience. BMJ Open Respir Res 2020;7:e000731.

12 Tang J, Li W, Jiang F, et al. Successfully treatment of application awake extracorporeal membrane oxygenation in critical COVID-19 patient: a case report. J Cardiothorac Surg 2020;15:335

13 Yun K, Lee JS, Kim EY, et al. Severe COVID-19 illness: risk factors and its burden on critical care resources. Front Med 2020;7:583060.

14 The Norwegian Institute of public health. COVID-19. Week 29 report. Oslo, Norway 2020.

15 Armstrong RA, Kane AD, Cook TM. Outcomes from intensive care in patients with COVID-19: a systematic review and meta-analysis of observational studies. Anaesthesia 2020;75:1340-9.

16 Rhodes A, Ferdinande $\mathrm{P}$, Flaatten $\mathrm{H}$, et al. The variability of critical care bed numbers in Europe. Intensive Care Med 2012:38:1647-53.

17 Norwegian Nurses Organization. Inngripende. Lange vakter. Mangler utstyr. Her er koronahverdagen med sykepleieres egne ord [Invading. Long shifts. Lack of equipment. Here is the nurses own description of corona weekday]. Oslo, Norway 2020.

18 Tabah A, Ramanan M, Laupland KB, et al. Personal protective equipment and intensive care unit healthcare worker safety in the COVID-19 era (PPE-SAFE): an international survey. J Crit Care 2020:59:70-5.

19 Barello S, Palamenghi L, Graffigna G. Burnout and somatic symptoms among frontline healthcare professionals at the peak of the Italian COVID-19 pandemic. Psychiatry Res 2020;290:113129.

20 Goh KJ, Wong J, Tien J-CC, et al. Preparing your intensive care unit for the COVID-19 pandemic: practical considerations and strategies. Crit Care 2020;24:215.

21 Liu M, Cheng S-Z, Xu K-W, et al. Use of personal protective equipment against coronavirus disease 2019 by healthcare professionals in Wuhan, China: cross sectional study. BMJ 2020;369:m2195.

22 von Elm E, Altman DG, Egger M, et al. Strengthening the reporting of observational studies in epidemiology (STROBE) statement: guidelines for reporting observational studies. BMJ 2007;335:806-8.

23 Pedersen MJB, Gjerland A, Rund BR, et al. Emergency preparedness and role clarity among rescue workers during the terror attacks in Norway July 22, 2011. PLoS One 2016;11:e0156536.

24 Soong JTY, Poots AJ, Bell D. Finding consensus on frailty assessment in acute care through Delphi method. BMJ Open 2016;6:e012904.

25 Hosmer DW, Lemeshow S, RX S. Applied Logistic Regression. 3rd ed: John Wiley \& Sons, Inc 2013.

26 The Norwegian Institute of Public Health. Coronavirus disease advice and information, 2020. Available: https://www.fhi.no/en/id/ infectious-diseases/coronavirus/

27 Grasselli G, Zangrillo A, Zanella A, et al. Baseline characteristics and outcomes of 1591 patients infected with SARS-CoV-2 admitted to ICUs of the Lombardy region, Italy. JAMA 2020;323:1574-81.

28 Choi GYS, Wan WTP, Chan AKM, et al. Preparedness for COVID-19: in situ simulation to enhance infection control systems in the intensive care unit. Br J Anaesth 2020;125:e236-9.

29 Centers for Disease Control and Prevention, (CDC). Coronavirus disease 2019 (COVID-19) for healthcare professionals, 2020. Available: https://www.cdc.gov/coronavirus/2019-nCoV/hcp/index. html 
30 González-Gil MT, González-Blázquez C, Parro-Moreno Al, et al. Nurses' perceptions and demands regarding COVID-19 care delivery in critical care units and hospital emergency services. Intensive Crit Care Nurs 2021;62:102966.

31 Sharma M, Creutzfeldt CJ, Lewis A, et al. Health-Care professionals' perceptions of critical care resource availability and factors associated with mental well-being during coronavirus disease 2019 (COVID-19): results from a US survey. Clin Infect Dis 2021;72:e566-76.

32 Barranco R, Ventura F. Covid-19 and infection in health-care workers: an emerging problem. Med Leg J 2020;88:65-6.

33 Sim MR. The COVID-19 pandemic: major risks to healthcare and other workers on the front line. Occup Environ Med 2020;77:281-2.
34 Emami A, Javanmardi F, Pirbonyeh N, et al. Prevalence of underlying diseases in hospitalized patients with COVID-19: a systematic review and meta-analysis. Arch Acad Emerg Med 2020;8:e35.

35 Unoki T, Sakuramoto $\mathrm{H}$, Sato $\mathrm{R}$, et al. Adverse effects of personal protective equipment among intensive care unit healthcare professionals during the COVID-19 pandemic: a scoping review. SAGE Open Nurs 2021;7:23779608211026164.

36 Lasalvia A, Amaddeo F, Porru S, et al. Levels of burn-out among healthcare workers during the COVID-19 pandemic and their associated factors: a cross-sectional study in a tertiary hospital of a highly burdened area of north-east Italy. BMJ Open 2021:11:e045127.

37 Shurlock J, Rudd J, Jeanes A, et al. Communication in the intensive care unit during COVID-19: early experience with the Nightingale communication method. Int J Qual Health Care 2021;33:mzaa162. 